\title{
The Establishment of Core Curriculum Group of Chemical Engineering and Technology and the Exploration and Practice on the Joint Teaching Model in the Group
}

\author{
Dai Chuanbo, Li Ruiduan, Kong Li, Wang Weidong, Zhang Jibo \\ Institute of Petrochemical Technology, Jilin Institute of Chemical Technology, Jilin, China
}

Keywords: curriculum group; joint teaching; teaching model

\begin{abstract}
The paper discusses the internal correlation among core curriculums in the chemical engineering and technology. By integrating courses, joint construction and teaching, a main line is found to enhance the engineering abilities of students. And the establishment of curriculum group has strengthened the correlation among courses, avoiding course overlapping as well as the waste of class hour. It adopts a teaching model characterized by joint teaching in the group, and analysis of typical cases, which integrates all knowledge, enabling students to realize the significance and practicality of expertise in the practical projects, arouse their enthusiasm, and raise their consciousness of engineering and innovation.
\end{abstract}

\section{Introduction}

The curriculum group in universities and colleges has witnessed more than 20 years of development, and the discussion about its meaning varies. Despite various meanings, the basic idea in constructing curriculum group is to build a close relationship among contents, and develop a curriculum group with strong internal logic to train a special skill. That is to say, the border among courses should be broken, and the independence of curriculum should be lessen to make their nature of service prominent for common skills, becoming coherent in a higher level.

\subsection{The building and application of curriculum group at home}

In 1990, the Beijing Institute of Technology proposed the study and construction of "curriculum group" based on the goal of overall optimization of teaching plan in the curriculum construction, thereby, starting the research on curriculum group. [1] And the building of curriculum group has attracted more attention although it has not achieved the ideal effect. [2,3] The reason for it lies in the various types of curriculums, complicated curriculum integration involving so many teachers without efficient application, bringing great difficulty for uniting ideas and teaching, and for deepening related discussion.

\subsection{The building and application of curriculum group at abroad}

Although the concept of "curriculum group" has not been clarified at abroad, many universities and colleges in developed countries have attached much importance to the comprehensive curriculum setting to cultivate comprehensive abilities of students in practice. Some prestigious universities have even built effective core curriculums, and opened diversified comprehensive curriculums in order to train all-round capabilities of students efficiently.

\section{The significance and advantages of the building curriculum group}

As China has focused more on the engineering education, the higher education has undergone in-depth reform gradually, and the core curriculums in the chemical engineering have been reduced. Thus, how to improve the teaching quality, cultivate innovative and qualified talents in this field in a short time has become a hotspot in the chemical engineering education. To solve this problem, the paper discussed the internal correlation among curriculums, integrated and taught curriculums jointly so as to seek for a major goal for engineering capability training and strengthen students' 
abilities in an efficient manner. The building of curriculum group has not only strengthened the connection among curriculums but avoided the overlapping of course and waste of class hour. The teaching model featured by joint teaching has linked much knowledge so as to make students notice the importance as well as application of the expertise in the real engineering.

Compared with the "independent" curriculum view, "curriculum group" boasts its unique characteristics and advantages in the teaching design, which mainly show in the following three respects: First, the combination of "curriculum group construction" with the discipline construction should give full play to the relevant discipline construction and integrate the discipline construction with the curriculum group. Some universities organize qualified teachers with strong scientific and research abilities to participate in the construction of curriculum group in the form of "teaching team”, improving the teaching and overall collaboration abilities of teachers. Second, related curriculums with close correlation shall be included into the curriculum group guided by system science, which realizes the goal of overall optimization and improves the efficiency as well as the benefits of the curriculum construction.

Third, unlike previous "independent” curriculum, the curriculum group takes theoretical teaching and related practice into consideration, conducts systematic study on the theoretical teaching, but makes a reform in the practical teaching, enhancing the teaching effect in an all-round way from various channels.

\section{The establishment of curriculum group and the specific content of joint teaching}

As for the chemical engineering and technology, the joint construction and teaching has been tried, and the core curriculum group of the chemical engineering consist of six curriculums: principles of chemical industry, chemical engineering thermodynamics, chemical reaction engineering, separation engineering, chemical engineering design and specialized experiment. Thus, joint course team has been set up to implement joint construction and teaching for course resources. The course team applied joint lesson preparation and mutual corroboration in teaching with comprehensive cases. By analyzing amount of professional knowledge related to cases deeply, the knowledge point has been connected into a line, and then a knowledge chain. As the main line, the knowledge chain has expanded the knowledge on it into a web, demonstrating all respects of professional knowledge systematically. In this way, students can learn comprehensive and systematic expertise by analyzing typical cases, therefore, they grasp knowledge points completely, achieving the goal of deep learning and mastering expertise.

The specific content is as follows:

(1) Integrate curriculum group and establish curriculum group

Given the correlation between the chemical engineering and technology, a joint course scheme is proposed. And a core curriculum group in the chemical engineering has been formed, including six courses: principles of chemical industry, chemical engineering thermodynamics, chemical reaction engineering, separation engineering, chemical engineering design and specialized experiment, which covers three levels: namely, basic knowledge, special knowledge, and professional application.

(2) Organize teaching content and set engineering cases

The typical case with social needs that has been applied in enterprises, is chosen as the point of breakthrough. By analyzing all respects of professional knowledge related to the case deeply, such professional knowledge is connected into a line, and then, a chain, which is expanded as a web to lead students to learn expertise completely and systematically by means of a classic case.

(3) Establish curriculum group, prepare lessons all at once, and teach mutually

Teachers in the same curriculum group are organized to establish a team, and discuss regularly, arrange the course content, engineering case design and analysis in a unified manner to realize lesion preparation all at once and hierarchical teaching. In the preparation, the correlation between the knowledge shall be strengthened, and connection among courses shall be increased, and mutual supplementation shall be made to lay a solid theoretical foundation for students, shaping a three-level teaching system covering theoretical method, technological means and engineering 
application. While in teaching, the curriculum team discusses regularly so as to build a united and comprehensive knowledge system.

(4) Reform of assessment method

The assessment method will undergo a reform to link basic theories with practice, and implement close-book and open-book examinations simultaneously. The assessment includes both traditional theoretical exam and practical applied abilities. The single final exam scoring system will be changed to a rational and all-round assessment method, which includes usual performance, major project, and final exam.

\section{Implementation measures}

The curriculum team will establish a curriculum group to organize and manage the research team led by the project leader. They will work out a program according to the research topic, and adjust the implementation in practice, summarize research results timely to ensure proper and efficient research work.

(1) The team leader will establish and manage the curriculum group, arrange the team members, and coordinate their work, divergence, and views. On the other hand, team members should follow the orders of the leader, finish work as planned, meanwhile, they should cooperate with each other to conduct the research project orderly and efficiently.

(2) College leaders coordinate teachers to cooperate with each other to finish teaching tasks

(3) The college and department leaders arrange senior professors to integrate teaching content, select appropriate cases, and assist in contacting enterprises to provide practical materials of enterprise production cases.

(4) The college and department leaders give support from policy to change the assessment method and system.

(5) The college and department leaders give a certain amount of work or service fee to the teachers who participate in the construction and practice of the curriculum group, and praise the teachers taking charge of teaching.

\section{Conclusions}

The joint teaching in the curriculum group has not only strengthened the correlation among courses, but avoided overlapping of courses and the waste of class hour. Teaching is arranged in the form of project cases to link all knowledge for students to realize the significance and practicality of the expertise in the practical application, which stimulates students' interests and raises their awareness of engineering. Students, thus, apply what they have learned, and learn in order to practice, enhancing their enthusiasm for leaning and creativity, greatly recognizing the significance of knowledge. The implementation of the teaching model has obviously eliminated the weariness for learning and hooky, creating a sound atmosphere on the campus, ultimately, bringing up applied talents in the chemical engineering meeting needs of enterprises and the society.

\section{References}

[1] Wang Jiacai, Yang Shiyi, Huo Yaling, et al. Study on the evaluation index system of class group and its quality inspection [J]. Higher engineering education research, 1999, (S1):71-73.

[2] Sun Cunchang. On the construction of "four-level system" of college curriculum group [J]. University education science, 2008, (5):46-48.

[3] Zhao Chaohui. Discussion on the construction of curriculum group [J]. China science and education innovation guidance, 2008, (14):17-18.

[4] Long Chunyang. Curriculum group construction: the path choice for the reform of college curriculum teaching [J]. Modern education science, 2010, (2):139-141. 
[5] Cao Bin, Wang Ying. Thoughts and principles on the construction of curriculum group in postmodern universities [J]. Education, 2009, (2):37.

[6] Lu Xuxiang, Yan Xiaozhong. The development of curriculum group and the enlightenment on the construction of energy power specialty courses [J]. China electric power education, 2014, (14):79-81.

[7] Liu Huie, Song Chunmin, Ding Chuanqin, etc. Combined with the courses to improve the teaching effect of chemical courses [J]. Chemical industry higher education,2015(5),22-25.

[8] Huang Guowen, Chen Zhi, Xu Junqiang, et al. "Integrated" teaching model of chemical industry based on typical cases [J]. Scientific consultation, 2013 (01), 69-70. 